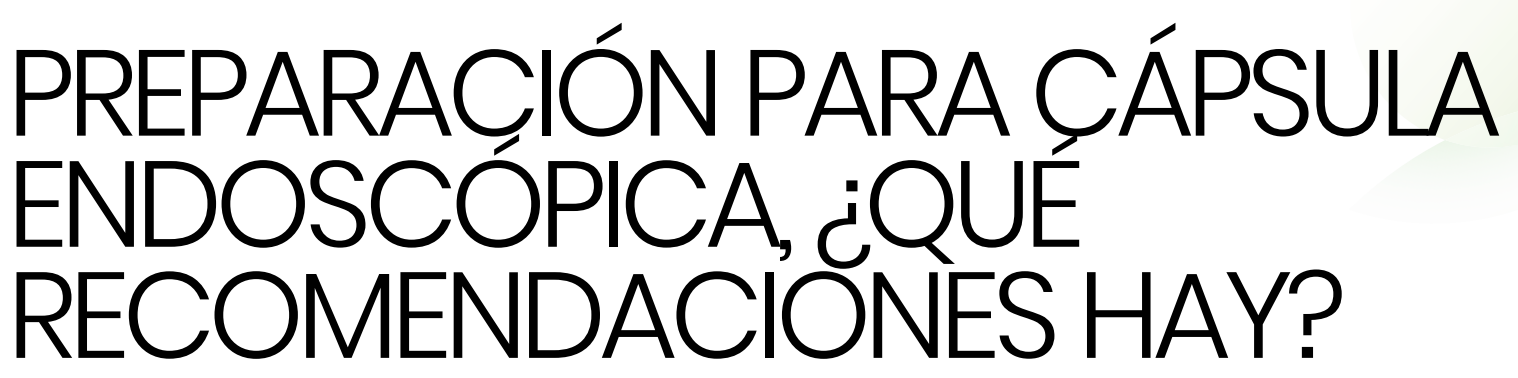

\title{
PREPARATION FOR CAPSULE ENDOSCOPY, WHAT RECOMMENDATIONS ARE THERE?
}

\section{Díaz Alcázar MM, Casado Caballero FJ}

Hospital Universitario Clínico San Cecilio. Granada.
Palabras clave: cápsula endoscópica, preparación intestinal, visualización mucosa.

Keywords: capsule endoscopy, bowel preparation, mucosal visualization.

\section{Cuerpo}

La introducción de la cápsula endoscópica supuso un enorme avance en la evaluación del intestino delgado, permitiendo un método no invasivo para la valoración intestinal. Pero ¿qué recomendaciones

\section{CORRESPONDENCIA}

María del Mar Díaz Alcázar

Hospital Universitario Clínico San Cecilio

18016 Granada

mmardiazalcazar@gmail.com

Fecha de envio: 02/01/2021

Fecha de aceptación: 21/03/2021 hay para optimizar la visualización mucosa y aumentar el rendimiento diagnóstico?

La preparación óptima para la cápsula es controvertida ${ }^{1-2}$. Una preparación insuficiente compromete la precisión diagnóstica e incrementa el coste y las molestias del paciente ${ }^{2,3}$.

Se han desarrollado varios estudios para determinar si la preparación con purgantes, antiespumantes y/o procinéticos mejora la visualización mucosa, el rendimiento diagnóstico y la tasa de exploraciones finalizadas ${ }^{1,2}$. De ellos, cuatro metaanálisis concluyen que el polietilenglicol mejora la visualización ${ }^{1,2}$. Según esto, la sociedad europea de endoscopia digestiva ESGE recomienda modificaciones dietéticas e ingesta de 2 litros de polietilenglicol y antiespumantes, mientras que no recomienda la administración rutinaria de procinéticos ${ }^{1-4}$. Sin embargo, reconoce que no hay datos concluyentes sobre la tasa de exploraciones finalizadas, el rendimiento diagnóstico y la dosis y el momento óptimo para la ingesta de purgantes ${ }^{1-4}$. 
Otros autores consideran que los resultados son contradictorios y no hay evidencia suficiente para estas recomendaciones ${ }^{2,4}$. Según un estudio ${ }^{3}$, la preparación no mejora significativamente la visualización mucosa ni la precisión diagnóstica en comparación con el ayuno, aunque sí mejora la tasa de exploraciones completadas, aunque a costa de mayores molestias del paciente, lo que influiría en la adherencia ${ }^{2}$. El análisis de 12 estudios aleatorizados y controlados tampoco apoya el uso de purgantes antes de la cápsula ${ }^{4}$. Estos autores proponen valorar nuevas opciones como la administración de purgantes tras la ingesta de la cápsula, tras confirmar que ha llegado al intestino delgado ${ }^{2,4}$. Además, los purgantes podrían dificultar la interpretación, ya que si se lava la sangre dificultaría saber si una lesión vascular es la causa del sagrado o un hallazgo incidental ${ }^{4}$. Sin embargo, si se sospecha enfermedad de Crohn o tumores de intestino delgado los purgantes sí podrían mejorar la visualización ${ }^{4}$.

\section{Bibliografía}

1. Rondonotti E, Spada C, Adler S, May A, Despott EJ, Koulaouzidis A, et al. Small-bowel capsule endoscopy and device-assisted enteroscopy for diagnosis and treatment of small-bowel disorders: European Society of Gastrointestinal Endoscopy (ESGE) Technical Review. Endoscopy 2018;50(4):423-446. doi: 10.1055/a-0576-0566.

2. Xavier S, Rosa B, Monteiro S, Arieira C, Magalhães R, Cúrdia Gonçalves $T$, et al. Bowel preparation for small bowel capsule endoscopy - The later, the better! Dig Liver Dis 2019;51(10):1388-1391. doi: 10.1016/j.dld.2019.04.014.

3. Hansel SL, Murray JA, Alexander JA, Bruining DH, Larson MV, Mangan $\mathrm{TF}$, et al. Evaluating a combined bowel preparation for small-bowel capsule endoscopy: a prospective randomized-controlled study. Gastroenterol Rep (Oxf) 2019;8(1):31-35. doi: 10.1093/gastro/goz054.

4. Gkolfakis P, Tziatzios G, Triantafyllou K. Purgative small bowel preparation for capsule endoscopy? Maybe, but think out of the box! Dig Dis Sci 2020;65(1):336-7. doi: 10.1007/s10620-019-05896-w. 